\title{
Espécies vegetais para cobertura do solo: influência sobre plantas daninhas e a produtividade do algodoeiro em sistema plantio direto
}

\author{
Alexandre Cunha de Barcellos Ferreira', Fernando Mendes Lamas²
}

\begin{abstract}
RESUMO
Este trabalho objetivou avaliar a produção, a persistência e os efeitos de coberturas vegetais sobre as plantas daninhas e a produtividade do algodoeiro em sistema plantio direto. Os tratamentos consistiram das espécies de cobertura: milheto (Pennisetum glaucum (L.) R. Brown), Brachiaria ruziziensis Germain \& Evrard, sorgo forrageiro (Sorghum bicolor L. Moench), capim-pé-de-galinha (Eleusine coracana L. Gaerth), Crotalaria juncea L., Crotalaria spectabilis Roth, aveia-preta (Avena strigosa Schreb.), nabo forrageiro (Raphanus sativus L.), P. glaucum + C. juncea, P. glaucum + C. spectabilis, B. ruziziensis + C. juncea, B. ruziziensis + C. spectabilis, S. bicolor + C. juncea, S. bicolor + C. spectabilis, E. coracana $+C$. juncea, E. coracana $+C$. spectabilis, A. strigosa $+R$. sativus, P. glaucum $+R$. sativus e pousio. As espécies foram semeadas no final do verão, após a colheita de soja, e o algodoeiro BRS 269-Buriti, nove meses após. O delineamento experimental foi em blocos ao acaso, com quatro repetições. As espécies B. ruziziensis, $B$. ruziziensis $+C$. juncea, $B$. ruziziensis $+C$. spectabilis e $P$. glaucum $+R$. sativus produziram mais de $6,8 \mathrm{t} \mathrm{ha}^{-1}$ de biomassa seca. A palhada produzida pela $B$. ruziziensis garantiu boa cobertura do solo durante o ciclo do algodoeiro. A biomassa seca de $B$. ruziziensis, $B$. ruziziensis $+C$. juncea e $B$. ruziziensis $+C$. spectabilis reduziu a infestação de plantas daninhas até a época de semeadura do algodão e durante os estádios iniciais de seu desenvolvimento. Palhas de R. sativus e A. strigosa, solteiras e consorciadas, interferiram negativamente na produtividade do algodoeiro.
\end{abstract}

Palavras-chave: Gossypium hirsutum L. r. latifolium, plantio direto, plantas de cobertura, biomassa seca, invasoras.

\section{ABSTRACT}

\section{Cover crops: effects on weeds and cotton yield in no-tillage system}

The objective of this work was to evaluate the production, persistence and the effect of different cover crops on weed control and cotton yield in no-tillage system. The treatments included: Pennisetum glaucum; Brachiaria ruziziensis; Sorghum bicolor; Eleusine coracana; Crotalaria juncea; Crotalaria spectabilis; Avena strigosa; Raphanus sativus; P. glaucum + C. juncea; P. glaucum + C. spectabilis; B. ruziziensis + C. juncea; B. ruziziensis + C. spectabilis; S. bicolor + C. juncea; S. bicolor + C. spectabilis; E. coracana + C. juncea; E. coracana + C. spectabilis; A. strigosa $+R$. sativus; $P$. glaucum $+R$. sativus; fallow. The cover crops were sown in late summer, after soybean harvest. The cotton cultivar BRS 269-Buriti was sown nine months later. The experiment was carried out in a randomized complete block design with four replications. Dry matter of B. ruziziensis, B. ruziziensis + C. juncea, B. ruziziensis $+C$. spectabilis and P. glaucum $+R$. sativus was above $6.8 \mathrm{t} \mathrm{ha}^{-1}$. The dry matter produced by $B$. ruziziensis provided sufficient soil cover during the cotton cycle. Residues of B. ruziziensis, B. ruziziensis $+C$. juncea and B. ruziziensis + C. spectabilis reduced weed incidence until the time of cotton sowing, lasting until the initial stages of cotton development. The use of both $R$. sativus and A. strigosa, alone or in mixtures, resulted in reduced yield of cotton fiber.

Key words: Gossypium hirsutum L. r. latifolium, cover crops, dry matter, no-tillage, weeds.

Recebido para publicação em maio de 2008 e aprovado em novembro de 2010

${ }^{1}$ Engenheiro-Agrônomo. Doutor. Pesquisador da Embrapa Algodão, Núcleo de Goiás, C.P. 179, 75375-000, Santo Antônio de Goiás, GO, Brasil. acunha@cnpa.embrapa.br

Engenheiro-Agrônomo. Doutor. Pesquisador da Embrapa Agropecuária Oeste, C.P. 661, 79804-970, Dourados, MS, Brasil. lamas@cpao.embrapa.br 


\section{INTRODUÇÃO}

Na cotonicultura praticada no cerrado brasileiro, que corresponde a mais de $90 \%$ da área e da produção nacionais, prevalece o sistema convencional de preparo do solo, caracterizado pela sua intensa mobilização por meio do uso de arados e, principalmente, de grades. Esse sistema de manejo tem ocasionado a degradação das propriedades físicas, químicas e biológicas do solo e, gradativamente, diminui o seu potencial produtivo.

Nas condições tropicais, a tecnologia do sistema plantio direto mostra-se bastante promissora para a conservação do solo (Fageria \& Stone, 2004), e um dos requisitos para garantir a eficiência desse sistema é a sua adequada cobertura exercida pelas espécies formadoras de palha (Hernani \& Salton, 2001). Elas devem ter boa produção de biomassa e ser suficientemente persistentes na proteção física do solo e disponibilização de nutrientes durante os períodos de excesso ou escassez de água (Nunes et al., 2006). No caso do algodoeiro, em virtude do longo tempo em que a cultura permanece no campo, que em alguns casos pode ser superior a 200 dias, a persistência da palha na superfície do solo deve ser alta, de forma que os benefícios de sua cobertura sejam auferidos.

A camada de palha sobre a superfície do solo funciona como atenuadora ou dissipadora de energia, protegeo contra o impacto direto das gotas de chuva, atua como obstáculo ao movimento do excesso de água que não infiltra no solo e impede o transporte de partículas minerais e orgânicas pela enxurrada (Heckler et al., 1998).

Com o adequado aporte de palha no sistema plantio direto, o controle de plantas daninhas pela palha pode ser superior a 90\% (Mateus et al., 2004). Lamas \& Staut (2006), avaliando diversas espécies para produção de palha nas condições de Mato Grosso, verificaram que a cobertura de Brachiaria ruziziensis reduziu significativamente a população de plantas daninhas na cultura do algodoeiro.

De acordo com Pavinato (2005), uma das dificuldades para o cultivo do algodoeiro no sistema plantio direto é a falta de opções de espécies vegetais para uso como cobertura do solo e formação de palha, adaptadas às condições do cerrado brasileiro. A semeadura de espécies formadoras de palha, no período da primavera, antecedendo a semeadura do algodão, não disponibiliza a quantidade suficiente para o sistema plantio direto e, ainda, não há persistência dessas coberturas no solo durante o ciclo do algodoeiro (Ferreira et al., 2007).

Realizou-se este trabalho com o objetivo de avaliar a produção, a facilidade de manejo químico com herbicidas e a persistência da biomassa seca de espécies vegetais semeadas após a colheita da soja, bem como os seus efeitos sobre a incidência de plantas daninhas e produtividade do algodoeiro nas condições do cerrado do Estado de Goiás.

\section{MATERIAL E MÉTODOS}

O experimento foi instalado na Fundação de Apoio à Pesquisa e Desenvolvimento Agropecuário de Goiás - Fundação Goiás, em Santa Helena de Goiás, GO (17 50' 33" S; $50^{\circ} 35^{\prime} 58$ " W; altitude de $560 \mathrm{~m}$ ), em um solo classificado como Latossolo Vermelho. As precipitações pluviais e temperaturas máximas e mínimas registradas durante a condução do experimento são apresentadas na Tabela 1.

O experimento constou de 19 tratamentos, que consistiram das espécies de cobertura: milheto (Pennisetum glaucum), Brachiaria ruziziensis, sorgo forrageiro (Sorghum bicolor), capim-pé-de-galinha (Eleusine coracana), Crotalaria juncea, Crotalaria spectabilis, aveia-preta (Avena strigosa), nabo forrageiro (Raphanus sativus), P. glaucum + C. juncea, P. glaucum + C. spectabilis, B. ruziziensis + C. juncea, B. ruziziensis $+C$. spectabilis, S. bicolor + C. juncea, S. bicolor + C. spectabilis, E. coracana + C. juncea, E. coracana + C. spectabilis, A. strigosa $+R$. sativus, $P$. glaucum $+R$. sativus e pousio ou testemunha com plantas daninhas voluntárias.

Dez dias após a colheita da soja, cultivar BRSGO 204Goiânia, a área foi sulcada mecanicamente em espaçamento de 0,45 m entre linhas e as espécies foram semeadas manualmente. Nos tratamentos com consórcio de espécies, elas foram semeadas na mesma linha e profundidade. Nenhuma espécie recebeu qualquer tipo de adubação ou irrigação.

Utilizou-se delineamento experimental de blocos ao acaso, com quatro repetições. Cada parcela foi de 10,0 x $10,0 \mathrm{~m}\left(100 \mathrm{~m}^{2}\right)$.

Trinta dias antes da semeadura do algodão foram obtidas ao acaso, por meio de um quadrado de ferro, três amostras por parcela de biomassa verde das espécies de cobertura, cada uma em $0,25 \mathrm{~m}^{2}$, para posterior secagem e determinação da biomassa seca. Após a amostragem, foi feito o manejo das plantas formadoras de palha por meio de herbicidas [3,0 $\mathrm{L} \mathrm{ha}^{-1}$ de glifosato $360 \mathrm{~g} \mathrm{~L}^{-1}$ do equivalente ácido (e.a.) $+60 \mathrm{~mL}$ de carfentrazona $400 \mathrm{~g} \mathrm{~L}^{-1}$ ]. Depois de 13 dias, foi avaliada visualmente, por dois avaliadores, a resposta das espécies ao manejo químico, por meio de uma escala percentual de notas, em que 0 (zero) correspondeu à ausência de controle e 100 à dessecação total das plantas de cobertura. Dois dias após, foi realizada outra pulverização, com $5 \mathrm{~L} \mathrm{ha}^{-1}$ de glifosato $360 \mathrm{~g} \mathrm{~L}^{-1}$ do e.a. $+50 \mathrm{~g} \mathrm{ha}^{-1}$ de flumioxazina $500 \mathrm{~g} \mathrm{~kg}^{-1}$, em todas as parcelas experimentais, em virtude da dificuldade de dessecação das duas espécies de crotalárias e de algumas plantas daninhas, principalmente de perpétua roxa (Centratherum punctatum Cass.). Trinta dias após a primeira dessecação foi realizada a semeadura direta do algodão, no espaçamento de 0,90 m entre fileiras e densidade de nove plantas pormetro. Em cada parcela com 10 x 10 
m foram dispostas 10 linhas de algodão; duas em cada lateral foram bordadura e as seis fileiras centrais restantes foram consideradas como área útil.

A adubação de semeadura foi feita com $400 \mathrm{~kg} \mathrm{ha}^{-1}$ de 4-30-16 + 0,5\% Zn + 0,4\% B. Adubações de cobertura foram realizadas no início da emissão do botão floral (B1) e no início do florescimento (F1), de acordo com Marur \& Ruano (2001), em cada uma utilizando-se $200 \mathrm{~kg} \mathrm{ha}^{-1}$ do formulado $20-0-30+0,2 \%$ de B.

Imediatamente após a semeadura do algodão foram aplicados os herbicidas de pré-emergência s-metolacloro $\left(0,8 \mathrm{~L} \mathrm{ha}^{-1}\right)$ e diuron $\left(2,0 \mathrm{~L} \mathrm{ha}^{-1}\right)$. Aos 47 dias após a emergência (DAE) do algodoeiro, antes da aplicação dos herbicidas em jato dirigido, as plantas daninhas presentes foram identificadas, e depois foi avaliado o percentual de cada uma das principais espécies presentes em cada parcela experimental.

As estimativas da produção e da persistência da biomassa seca pelas diferentes espécies vegetais foram realizadas por meio de amostragens em três épocas de avaliação: imediatamente antes da primeira dessecação (30 dias antes da semeadura - DAS) e aos 113 e 175 dias após a emergência (DAE).

Todas as amostragens das plantas daninhas e das espécies de cobertura, para as determinações da biomassa seca, foram realizadas por meio de três coletas, cada qual em $0,25 \mathrm{~m}^{2}$, tomadas ao acaso dentro da área útil da parcela. As amostras foram secas em estufa à temperatura de 65 ${ }^{\circ} \mathrm{C}$, até que a massa seca atingisse valor constante; depois foi determinada a biomassa seca, expressando-se os resultados em kg ha-1. $\mathrm{Na}$ amostragem para a determinação da biomassa seca das plantas daninhas elas não foram separadas por espécie.

Para a determinação do complexo de plantas daninhas, foram realizadas duas avaliações, uma antes da dessecação ou 30 dias antes da semeadura (30 DAS) e a outra aos
47 dias após a emergência (47 DAE) do algodoeiro, por dois diferentes avaliadores. As avaliações constaram da estimativa da porcentagem de cada espécie daninha presente em cada parcela. Com os dados de cada espécie daninha efetuou-se análise descritiva, calculando-se a média e o erro padrão nas diferentes repetições.

Na avaliação da porcentagem de cobertura do solo utilizou-se de um barbante com seis metros de comprimento, previamente marcado com 30 pontos equidistantes. Em cada parcela foram contados os pontos coincidentes do solo coberto com as palhas e calculada a porcentagem de cobertura. Em cada parcela foram realizadas três avaliações.

A colheita do algodão foi realizada aos 175 dias após a emergência. Para a avaliação da produtividade de algodão em caroço foram colhidas três linhas centrais da área útil da parcela, cada qual com seis metros de comprimento, perfazendo $18 \mathrm{~m}^{2}$, e os dados de produção em g parce$\mathrm{la}^{-1}$ foram transformados em $\mathrm{kg} \mathrm{ha}^{-1}$.

Nas três linhas colhidas foram previamente coletados 20 capulhos para a determinação da porcentagem de fibra e determinada a altura de cinco plantas ao acaso.

Os resultados obtidos foram submetidos à análise de variância, e a comparação de médias foi realizada por meio do teste de Scott-Knott, a 5\% de probabilidade de erro.

A correlação entre a biomassa das plantas de cobertura e a das plantas daninhas foi estimada pelo coeficiente de correlação de Pearson, a 1\% de probabilidade, pelo teste $\mathrm{t}$.

\section{RESULTADOS E DISCUSSÃO}

\section{Resposta das espécies formadoras de palha ao manejo químico de dessecação}

As espécies vegetais para formação de palha e posterior semeadura direta do algodoeiro apresentaram diferenças significativas (Tabela 2) quanto à resposta ao

Tabela 1. Precipitação pluvial mensal (mm) e temperaturas $\left({ }^{\circ} \mathrm{C}\right)$ máxima e mínima (média mensal) durante a condução do experimento

\begin{tabular}{|c|c|c|c|c|c|c|c|}
\hline Março*/06 & Abril/06 & Maio/06 & Junho/06 & Julho/06 & Agosto/06 & Set/06 & Out/06 \\
\hline \multicolumn{8}{|c|}{ Precipitação pluvial mensal (mm) } \\
\hline 237,6 & 72 & 6,2 & 0 & 0 & 40,4 & 29,6 & 284 \\
\hline \multicolumn{8}{|c|}{ Temperatura média mensal (máxima e mínima) } \\
\hline 32,6 & 32,2 & 30 & 30,3 & 31,4 & 34 & 34,3 & 33,8 \\
\hline 21,3 & 19,7 & 13,4 & 13,4 & 12,2 & 14 & 17,2 & 20,5 \\
\hline Nov/06 & Dez/06 & Jan/07 & Fev/07 & Março/07 & Abril/07 & Maio/07 & Junho/07 \\
\hline \multicolumn{8}{|c|}{ Precipitação pluvial mensal (mm) } \\
\hline 300,4 & 601,2 & 335,4 & 253,2 & 129,6 & 44 & 25,6 & 3,6 \\
\hline \multicolumn{8}{|c|}{ Temperatura média mensal (máxima e mínima) } \\
\hline 33 & 32,7 & 33,4 & 33 & 34,4 & 34,3 & 30,4 & 33,4 \\
\hline 20,5 & 21,5 & 21,8 & 21,2 & 19,7 & 19 & 14,9 & 12,9 \\
\hline
\end{tabular}

* A partir do dia 10 de março de 2006, dia da semeadura das espécies de cobertura. 
processo de dessecação na avaliação realizada 13 dias após a aplicação dos herbicidas glifosato $360 \mathrm{~g} \mathrm{~L}^{-1}$ do e.a. (3,0 L ha $\left.{ }^{-1}\right)+$ carfentrazona $400 \mathrm{~g} \mathrm{~L}^{-1}\left(60 \mathrm{~mL} \mathrm{ha}^{-1}\right)$ (Scott-Knott, $\mathrm{P}<0,05$ ).

Todos os tratamentos do grupo B. ruziziensis apresentaram os melhores resultados de dessecação. Nos casos do pousio, do R. sativus, da A. strigosa e do consórcio A. strigosa $+R$. sativus foram consideradas na avaliação apenas as plantas daninhas, pois no primeiro não foi semeada nenhuma espécie de cobertura, e nos outros três as espécies encerraram o ciclo de vida durante o período do outono/inverno, e já se encontravam mortas por ocasião da primeira aplicação dos herbicidas dessecantes. As espécies $C$. spectabilis e $C$. juncea, semeadas em sistema solteiro ou consorciadas com outras, foram as que apresentaram a maior dificuldade para o manejo químico com herbicidas, com exceção dos consórcios com $B$. ruziziensis, em que a gramínea exerceu forte poder de competição sobre as duas espécies de crotalária, as quais permaneceram viáveis por curto período no interior das parcelas, até que a $B$. ruziziensis formasse grande quantidade de massa vegetativa e dominasse o ambiente.

Tabela 2. Resposta das espécies de cobertura ao manejo químico de dessecação, 13 dias após a primeira aplicação dos herbicidas glifosato (3,0 L ha ${ }^{-1}, 360 \mathrm{~g} \mathrm{~L}^{-1}$ do equivalente ácido) $+60 \mathrm{~mL} \mathrm{ha}^{-1}$ de carfentrazona $400 \mathrm{~g} \mathrm{~L}^{-1}$

\begin{tabular}{lc}
\hline Espécies de cobertura & $\begin{array}{c}\text { Efeito da } \\
\text { dessecação } \\
(\%) *\end{array}$ \\
\hline Raphanus sativus** & $90,0 \mathrm{a}$ \\
Brachiaria ruziziensis & $87,5 \mathrm{a}$ \\
Brachiaria ruziziensis + Crotalaria juncea & $85,0 \mathrm{a}$ \\
Brachiaria ruziziensis + Crotalaria spectabilis & $82,5 \mathrm{a}$ \\
Eleusine coracana & $65,0 \mathrm{~b}$ \\
Pennisetum glaucum & $62,5 \mathrm{~b}$ \\
Pousio ** & $57,5 \mathrm{c}$ \\
Avena strigosa + Raphanus sativus ** & $55,0 \mathrm{c}$ \\
Pennisetum glaucum + Raphanus sativus & $55,0 \mathrm{c}$ \\
Avena strigosa** & $52,5 \mathrm{c}$ \\
Sorghum bicolor & $37,5 \mathrm{~d}$ \\
Sorghum bicolor + Crotalaria juncea & $37,5 \mathrm{~d}$ \\
Sorghum bicolor + Crotalaria spectabilis & $35,0 \mathrm{~d}$ \\
Pennisetum glaucum + Crotalaria juncea & $35,0 \mathrm{~d}$ \\
Crotalaria juncea & $35,0 \mathrm{~d}$ \\
Pennisetum glaucum + Crotalaria spectabilis & $32,5 \mathrm{~d}$ \\
Eleusine coracana + Crotalaria juncea & $32,5 \mathrm{~d}$ \\
Eleusine coracana + Crotalaria spectabilis & $30,0 \mathrm{~d}$ \\
Crotalaria spectabilis & $27,5 \mathrm{~d}$ \\
\hline C.V. (\%) & 22,4 \\
\hline Esca &
\end{tabular}

* Escala percentual de notas, em que 0 (zero) correspondeu à ausência de controle e 100 à dessecação total das plantas de cobertura. Médias seguidas de mesma letra, na coluna, não diferem entre si pelo teste de agrupamento de Scott-Knott $(\mathrm{P}<0,05)$. ${ }^{* *}$ Foi avaliada a eficiência de dessecação apenas das plantas infestantes.

\section{Biomassa seca e persistência no solo das espécies formadoras de palha}

Na avaliação realizada 30 dias antes da semeadura (30 DAS), imediatamente antes da primeira aplicação de herbicidas de manejo para a dessecação das espécies de cobertura, foi possível discriminar, pelo teste Scott-Knott $(\mathrm{P}<0,05)$, três grupos de espécies quanto à produção de biomassa seca, com destaque para $B$. ruziziensis, $B$. ruziziensis $+C$. juncea, $B$. ruziziensis $+C$. spectabilis e $P$. glaucum $+R$. sativus, com produção de matéria seca superior a 6,8 t ha ${ }^{-1}$ (Tabela 3), quantidade essa considerada adequada para a semeadura direta e boa cobertura do solo (Alvarenga et al., 2001; Nunes et al., 2006).

Nas avaliações posteriores, verificou-se que os tratamentos com B. ruziziensis (B. ruziziensis, B. ruziziensis + $C$. juncea e $B$. ruziziensis $+C$. spectabilis) continuaram se destacando quanto à manutenção de boa quantidade de palha na superfície do solo, superior a 6,0 t ha-1 de biomassa seca na avaliação realizada aos 113 DAE, e superior a $4.900 \mathrm{~kg} \mathrm{ha}^{-1}$ aos 175 DAE (Tabela 3). Já o tratamento $P$. glaucum $+R$. sativus, que também foi destaque na produção de biomassa seca, apresentou aos 113 DAE baixa persistência no ambiente, com redução superior a 50\% da biomassa seca verificada inicialmente (Tabela 3).

Na avaliação realizada aos 175 DAE, imediatamente após a colheita do algodão, observou-se que apenas nos tratamentos contendo B. ruziziensis a quantidade de biomassa seca na superfície do solo foi superior a $4.900 \mathrm{~kg} \mathrm{ha}^{-1}$ (Tabela 3 ), o que pode ser considerado excelente quantidade residual de palha no sistema, analisando-se o período de 209 dias, compreendido entre a primeira dessecação e amostragem das palhas e a colheita do algodão. De novembro a abril, nas condições do cerrado de Goiás, normalmente a temperatura do ar e o teor de água do solo são elevados, razão pela qual geralmente é rápida a decomposição da fitomassa da maioria das espécies de cobertura sobre o solo, especialmente as de baixa relação C/N. Além das condições climáticas (Calegari et al., 1993), a taxa de decomposição dos materiais de cobertura é função da relação $\mathrm{C} / \mathrm{N}$ do material vegetal, da quantidade de palha, da fertilidade do solo, da mesofauna, da atividade microbiológica do solo e do manejo da cobertura (Floss, 2000; Alvarenga et al., 2001).

A palha de nabo forrageiro, que possui reduzida relação $\mathrm{C} / \mathrm{N}$, foi rapidamente decomposta antes mesmo da dessecação para a semeadura do algodão (Tabela 3), deixando o solo desprotegido, tal como observado por DePolli \& Chada (1989) e Borkert et al. (2003). Geralmente, as espécies vegetais com elevada relação $\mathrm{C} / \mathrm{N}$ são decompostas mais lentamente, porém fornecem baixa quantidade de nitrogênio à cultura sucessora (Aita \& Giacomini, 2003). Esses mesmos autores sugerem a mistura de leguminosas e gramíneas, pois além de proteger o solo e adicionar $\mathrm{N}$, o consórcio possibilita a produção de 
biomassa seca com relação C/N intermediária, de forma que a velocidade de decomposição dos resíduos vegetais não seja tão alta e o fornecimento de $\mathrm{N}$ à cultura comercial não seja baixo como seria apenas com o uso da gramínea.

A cobertura do solo, avaliada em março de 2007 (75 DAE), seguiu o comportamento da produção de biomassa seca, com melhor cobertura do solo pelas espécies com maior produção de biomassa (B. ruziziensis, $B$. ruziziensis $+C$. juncea e B. ruziziensis $+C$. spectabilis). Nesses tratamentos, a cobertura do solo, avaliada aos 75 DAE, foi superior a $80 \%$, o que pode ser considerado como excelente percentual.

Nos tratamentos pousio, C. juncea e A. strigosa as porcentagens de cobertura do solo, avaliadas aos $75 \mathrm{DAE}$, também foram altas (Tabela 3), mas em virtude quase que exclusivamente da incidência de plantas daninhas, uma vez que as espécies de cobertura produziram quantidades reduzidas de biomassa. A rápida decomposição do resíduo das espécies e a baixa cobertura inicial do solo possibilitaram o desenvolvimento da vegetação espontânea, o que resultou no aumento da biomassa na segunda amostragem. Nunes et al. (2006), que trabalharam com várias espécies de gramíneas e leguminosas, também observaram esse efeito. O tratamento S. bicolor $+C$. spectabilis também apresentou boa cobertura do solo aos 75 DAE (Tabela 3), proveniente tanto dos resíduos das duas espécies de cobertura quanto da biomassa seca das plantas daninhas, que correspondeu a $1.300 \mathrm{~kg} \mathrm{ha}^{-1}$.
Os resultados apresentados mostram que é possível cultivar o algodoeiro no sistema de semeadura direta no ambiente do cerrado, pois grande parte da palha de Brachiaria ruziziensis persiste no solo durante todo o ciclo da cultura.

\section{Incidência de plantas daninhas}

As principais plantas daninhas infestantes da área foram apaga-fogo (Alternanthera tenella Colla), perpétuaroxa (Centratherum punctatum), capim-colchão (Digitaria horizontalis Willd) e corda-de-viola (Ipomoea L. sp.), tanto por ocasião da avaliação realizada antes da dessecação ou 30 dias antes da semeadura (30 DAS) quanto aos 47 dias após a emergência (DAE) do algodoeiro (Tabela 4). Com menor intensidade de infestação foram observadas as espécies: erva-de-santa-luzia (Chamaesyce hirta L. Millsp, caruru (Amaranthus L. sp.), leiteiro (Euphorbia heterophylla L.), capim-pé-de-galinha (Eleusine indica L.) e trapoeraba (Commelina benghalensis L.). Nos tratamentos com B. ruziziensis, aos 30 DAS não houve infestação de plantas daninhas em virtude da alta quantidade de biomassa formada pela espécie de cobertura. Aos 47 DAE do algodoeiro, embora houvesse bastante palha de cobertura no solo nos tratamentos com B. ruziziensis, ocorreu infestação de plantas daninhas compostas de espécies de folhas largas e estreitas, sobretudo em virtude do revolvimento do solo na linha de semeadura.

Tabela 3. Biomassa seca, em $\mathrm{kg} \mathrm{ha}^{-1}$, das espécies vegetais de cobertura, antes da dessecação (30 dias antes da semeadura - DAS), aos 113 e 175 dias após a emergência do algodoeiro (113 e 175 DAE), e porcentagem (\%) de cobertura do solo aos 75 DAE

\begin{tabular}{|c|c|c|c|c|}
\hline \multirow{2}{*}{ Espécies de cobertura } & \multicolumn{3}{|c|}{ Biomassa seca $\left(\mathrm{kg} \mathrm{ha}^{-1}\right)$} & \multirow{2}{*}{$\%$ de cobertura } \\
\hline & 30 DAS & 113 DAE & 175 DAE & \\
\hline B. ruziziensis + C. spectabilis & 8417 a & 7783 a & 5478 a & $92,8 \mathrm{a}$ \\
\hline Brachiaria ruziziensis & 8183 a & 7497 a & 4926 a & 92,5 a \\
\hline B. ruziziensis $+C$. juncea & 9067 a & 7417 a & $5704 \mathrm{a}$ & $89,2 \mathrm{a}$ \\
\hline Sorghum bicolor + C. spectabilis & $4167 \mathrm{~b}$ & $4100 \mathrm{~b}$ & $1175 \mathrm{~b}$ & $79,4 \mathrm{~b}$ \\
\hline Sorghum bicolor & $5033 \mathrm{~b}$ & $3683 \mathrm{~b}$ & $1455 \mathrm{~b}$ & $78,3 \mathrm{~b}$ \\
\hline P. glaucum + Crotalaria juncea & $4183 \mathrm{~b}$ & $3317 \mathrm{~b}$ & $1726 b$ & $76,9 \mathrm{~b}$ \\
\hline P. glaucum $+C$. spectabilis & $4783 \mathrm{~b}$ & $3150 \mathrm{~b}$ & $1596 \mathrm{~b}$ & $74,7 \mathrm{~b}$ \\
\hline Pennisetum glaucum & $5200 \mathrm{~b}$ & 4050b & $2422 b$ & $74,7 \mathrm{~b}$ \\
\hline Eleusine coracana $+C$. juncea & $4733 \mathrm{~b}$ & $3233 \mathrm{~b}$ & $1088 \mathrm{~b}$ & $71,1 \mathrm{c}$ \\
\hline Sorghum bicolor $+C$. juncea & $4583 \mathrm{~b}$ & $3183 \mathrm{~b}$ & $1363 \mathrm{~b}$ & $70,6 \mathrm{c}$ \\
\hline P. glaucum + Raphanus sativus & 6817 a & 3333 c & $1645 \mathrm{~b}$ & $70,3 \mathrm{c}$ \\
\hline Crotalaria juncea & $4517 \mathrm{~b}$ & - & - & 67,5 c \\
\hline Eleusine coracana & $3217 \mathrm{~b}$ & 1617 c & $902 \mathrm{~b}$ & 67,2 c \\
\hline Eleusine coracana + C. spectabilis & $4233 \mathrm{~b}$ & $3067 \mathrm{~b}$ & $1126 \mathrm{~b}$ & $66,4 \mathrm{c}$ \\
\hline Crotalaria spectabilis & $4017 \mathrm{~b}$ & $2383 \mathrm{~b}$ & $906 \mathrm{~b}$ & 62,5 c \\
\hline Avena strigosa & $1700 \mathrm{c}$ & - & - & $60,8 * \mathrm{c}$ \\
\hline Pousio & 883 c & - & - & $53,3^{*} \mathrm{~d}$ \\
\hline Avena strigosa + Raphanus sativus & - & - & - & $31,7 * \mathrm{e}$ \\
\hline Raphanus sativus & - & - & - & $26,7 * \mathrm{e}$ \\
\hline C.V. $(\%)$ & 36,7 & 29,6 & 39,7 & 15,1 \\
\hline
\end{tabular}

Grupos de médias seguidas pela mesma letra, na coluna, não diferem entre si, pelo teste de Scott-Knott, a 5\%. * Porcentagem de cobertura exercida pelas plantas infestantes manejadas com herbicidas.

Rev. Ceres, Viçosa, v. 57, n.6, p. 778-786, nov/dez, 2010 


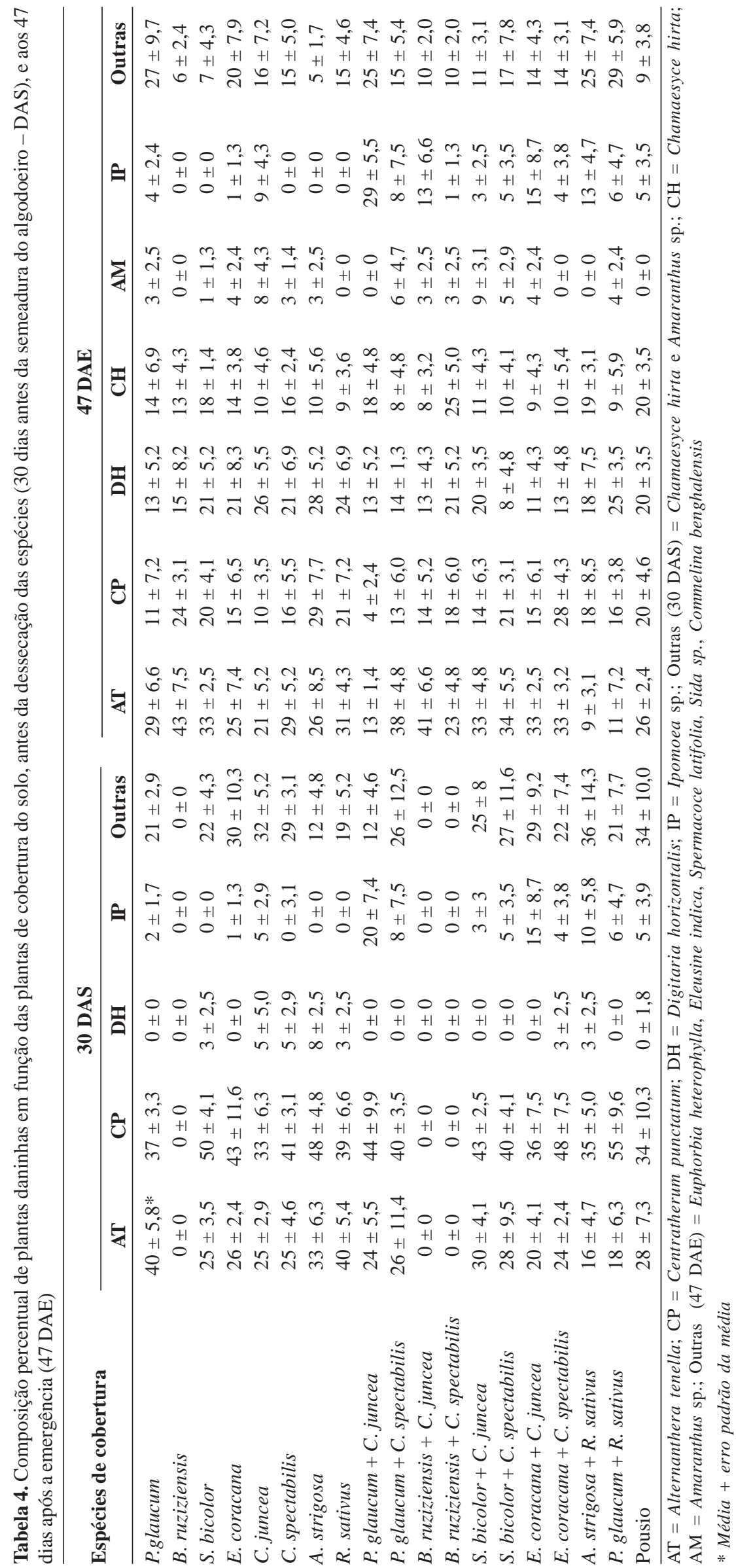


O efeito das espécies vegetais utilizadas para cobertura do solo sobre a biomassa seca das plantas daninhas foi estatisticamente significativo pelo teste $F$ tanto na avaliação realizada aos 30 DAS $(\mathrm{P}<0,01)$ como aos 47 DAE $(\mathrm{P}<0,01)$. As espécies $B$. ruziziensis, $B$. ruziziensis $+C$. juncea e $B$. ruziziensis $+C$. spectabilis promoveram controle de $100 \%$ das plantas daninhas na avaliação realizada aos 30 DAS (Tabela 5).

A cobertura do solo com resíduos vegetais de $B$. ruziziensis que apresenta alta relação $\mathrm{C} / \mathrm{N}$, além de proteger o solo, reduziu significativamente a densidade da população de plantas daninhas, conforme verificado também por Corrêa \& Sharma (2004), Mateus et al. (2004) e Lamas \& Staut (2006). Esse resultado confirma o potencial dessa espécie como estratégia para o manejo de plantas daninhas que pode, ao longo do tempo de adoção do sistema plantio direto, contribuir para a redução do custo de produção do algodoeiro. De acordo com Richetti (2007), o controle de plantas daninhas na cultura do algodoeiro por meio do uso de herbicidas corresponde entre 7 e $10 \%$ do custo de produção no cerrado. No sistema plantio direto, normalmente as sementes das plantas daninhas ficam localizadas próximo à superfície do solo (Yenish et al., 1992; Lacerda et al., 2005). Assim, ao longo do tempo, a tendência é de que o banco de sementes se reduza (Pitelli, 1997), devido à perda de viabilidade e à maior exposição à ação dos herbicidas. Além disso, as sementes que estão localizadas nas camadas mais profundas do solo têm sua capacidade competitiva prejudicada, pois a camada de palha sobre o solo dificulta e, às vezes, impede a emergência das invasoras (Correia \& Durigan, 2004; Correia, 2005). De acordo com Meschede et al. (2007), o acúmulo de biomassa pelas plantas de cobertura é inversamente proporcional ao da biomassa das plantas daninhas.

O nabo forrageiro diminuiu a incidência de plantas daninhas por ocasião da primeira aplicação dos herbicidas dessecantes (Tabela 5), devido provavelmente ao seu efeito alelopático (Almeida \& Rodrigues, 1995). Essa é uma boa característica dessa espécie, mas, por outro lado, ela pouco protegeu o solo devido à ínfima quantidade de palha formada e à rápida decomposição de seus resíduos. O nabo forrageiro apresentou curto ciclo de vida, tal como observado por Fleck et al. (2006), e em menos de 70 dias após a emergência já estava praticamente sem folhas e seco. Assim, quando o nabo forrageiro é semeado no final do verão, na condição do cerrado de Goiás, em regiões de altitude abaixo de $600 \mathrm{~m}$ e onde as chuvas após a semeadura se reduzem consideravelmente (Tabela 1), o seu crescimento é comprometido, sendo baixa sua viabilidade e persistência no solo.

Nos tratamentos com B. ruziziensis, apesar da boa cobertura do solo (Tabela 3), também houve infestação de plantas daninhas na avaliação realizada aos 47 DAE (Tabelas 4 e 5). Isso ocorreu, provavelmente, em virtude de que a máquina semeadora, equipada com o sistema de "botinha", revolveu o solo na linha de semeadura, possi-

Tabela 5. Efeito de coberturas vegetais sobre a biomassa seca das plantas daninhas, em $\mathrm{kg} \mathrm{ha}^{-1}$, antes da dessecação das espécies (30 dias antes da semeadura do algodoeiro - DAS), e aos 47 dias após a emergência (47 DAE)

\begin{tabular}{|c|c|c|}
\hline \multirow[t]{2}{*}{ Espécies de cobertura } & \multicolumn{2}{|c|}{ Biomassa seca $\left(\mathrm{kg} \mathrm{ha}^{-1}\right)$} \\
\hline & 30 DAS & $47 \mathrm{DAE}$ \\
\hline Brachiaria ruziziensis & $0,00 \mathrm{c}$ & $833,33 \mathrm{~b}$ \\
\hline B. ruziziensis + C. juncea & $0,00 \mathrm{c}$ & $900,00 \mathrm{~b}$ \\
\hline B. ruziziensis + C. spectabilis & 0,00 c & $533,33 \mathrm{~b}$ \\
\hline Raphanus sativus & $773,33 \mathrm{~b}$ & $733,33 \mathrm{~b}$ \\
\hline Sorghum bicolor $+C$. spectabilis & $900,00 \mathrm{~b}$ & $1300,00 \mathrm{a}$ \\
\hline P. glaucum + Raphanus sativus & $916,67 \mathrm{~b}$ & $616,67 \mathrm{~b}$ \\
\hline Pennisetum glaucum & $983,33 \mathrm{~b}$ & $933,33 \mathrm{~b}$ \\
\hline Eleusine coracana + C. spectabilis & $1000,00 \mathrm{~b}$ & $1000,00 \mathrm{~b}$ \\
\hline Pousio & $1016,66 \mathrm{~b}$ & $1016,67 \mathrm{~b}$ \\
\hline Eleusine coracana & $1150,00 \mathrm{~b}$ & $1200,00 \mathrm{a}$ \\
\hline Sorghum bicolor & 1350,00 a & $933,33 \mathrm{~b}$ \\
\hline Crotalaria spectabilis & 1366,67 a & $583,33 \mathrm{~b}$ \\
\hline Eleusine coracana $+C$. juncea & $1410,00 \mathrm{a}$ & $716,67 \mathrm{~b}$ \\
\hline P. glaucum $+C$. spectabilis & 1433,33 a & $583,33 \mathrm{~b}$ \\
\hline P. glaucum + Crotalaria juncea & $1450,00 \mathrm{a}$ & $583,33 \mathrm{~b}$ \\
\hline Avena strigosa + Raphanus sativus & $1600,00 \mathrm{a}$ & $650,00 \mathrm{~b}$ \\
\hline Sorghum bicolor $+C$. juncea & $1700,00 \mathrm{a}$ & $1550,00 \mathrm{a}$ \\
\hline Avena strigosa & 1783,33 a & 2016,67 a \\
\hline Crotalaria juncea & $2100,00 \mathrm{a}$ & $1438,00 \mathrm{a}$ \\
\hline C.V. (\%) & 54,13 & 54,46 \\
\hline
\end{tabular}

Grupos de médias seguidas pela mesma letra, na coluna, não diferem entre si pelo teste de Scott-Knott, a 5\%. 
bilitando a germinação das sementes das plantas daninhas, principalmente das espécies Alternanthera tenella, Centratherum punctatum, Chamaesyce hirta e Ipomoea sp. Outro motivo pode ter sido devido à germinação das sementes mais próximas da superfície do solo, conforme observado por Canossa et al. (2007), os quais verificaram que a presença de palha na superfície do solo não afetou a velocidade de emergência das plântulas de A. tenella e que as sementes posicionadas nas camadas mais superficiais do solo apresentaram velocidade de emergência superior às daquelas colocadas nas camadas mais profundas, independentemente da presença de palha na superfície do solo.

A biomassa das plantas daninhas correlacionou-se negativamente com a das plantas de cobertura. Na primeira avaliação, aos 30 DAS, o coeficiente de correlação foi de $-0,35$, significativo a $1 \%$ pelo teste t, e aos 47 DAE foi de $-0,14$, significativo a $5 \%$ pelo teste $t$. Assim, observase que quanto maior a biomassa das plantas de cobertura sobre o solo menor foi a incidência de plantas daninhas.

\section{Altura de plantas, porcentagem e produtividade de fibra}

Para a variável altura de planta, avaliada por ocasião da colheita do algodão, não houve diferença significativa entre os tratamentos (Tabela 6), de forma idêntica ao observado por Lamas (2007), em estudo conduzido no Estado de Mato Grosso.
Em relação à porcentagem e à produtividade de fibra, foi possível discriminar dois grupos de médias pelo teste de Scott-Knott $(\mathrm{P}<0,05)$, com destaque negativo para as espécies de cobertura S. bicolor, A. strigosa, E. coracana, $R$. sativus e $A$. strigosa $+R$. sativus, que reduziram significativamente a produtividade de fibra do algodoeiro (Tabela 6). A produtividade média de fibra foi de $1.513 \mathrm{~kg}$ ha${ }^{1}$, quando o algodoeiro foi cultivado sobre as palhas das espécies do grupo relativo à maior produtividade, e de $1.344 \mathrm{~kg} \mathrm{ha}^{-1}$ referente ao grupo de menor produtividade, correspondente aos tratamentos S. bicolor, A. strigosa, $E$. coracana, $R$. sativus e A. strigosa $+R$. sativus. A diferença entre esses dois grupos foi de $169 \mathrm{~kg} \mathrm{ha}^{-1}$ de fibra.

A produtividade do algodoeiro, quando cultivado sobre palhas das espécies E. coracana e S. bicolor, ambas na presença de $C$. juncea e $C$. spectabilis, foi superior à obtida apenas sobre a palhada da gramínea solteira (Tabela 6). A produtividade de fibra, quando o algodoeiro foi cultivado sobre palhada de P. glaucum e B. ruziziensis, não diferiu significativamente quando essas espécies foram cultivadas isoladas ou consorciadas com as duas espécies de crotalária. Esperava-se que a associação de gramíneas com as crotalárias resultasse em ganhos expressivos de produtividade, pois de acordo com Aita \& Giacomini (2003) o consórcio de espécies, além da maior diversidade, torna-se ainda mais vantajoso quando elas possuem relação $\mathrm{C} / \mathrm{N}$ diferente.

Tabela 6. Altura $(\mathrm{cm})$ de plantas na colheita, percentagem e produtividade $\left(\mathrm{kg} \mathrm{ha}^{-1}\right)$ de fibra em função das espécies de cobertura do solo

\begin{tabular}{|c|c|c|c|}
\hline Espécies de cobertura & Altura(cm) & $\begin{array}{c}\text { Percentagem } \\
\text { de fibra }(\%)\end{array}$ & $\begin{array}{c}\text { Produtividade } \\
\text { de fibra }\left(\mathrm{kg} \mathrm{ha}^{-1}\right)\end{array}$ \\
\hline Brachiaria ruziziensis + Crotalaria juncea & $106 \mathrm{a}$ & 40,16 a & 1596 a \\
\hline Eleusine coracana + Crotalaria juncea & $111 \mathrm{a}$ & 39,54 a & 1577 a \\
\hline Pennisetum glaucum + Crotalaria spectabilis & 107 a & $39,56 \mathrm{~b}$ & 1565 a \\
\hline Sorghum bicolor + Crotalaria spectabilis & 107 a & 40,86 a & 1553 a \\
\hline Brachiaria ruziziensis + C. spectabilis & $104 \mathrm{a}$ & $40,50 \mathrm{a}$ & 1536 a \\
\hline Pennisetum glaucum + Crotalaria juncea & $112 \mathrm{a}$ & $39,18 \mathrm{~b}$ & $1534 \mathrm{a}$ \\
\hline Sorghum bicolor + Crotalaria juncea & $106 \mathrm{a}$ & 40,21 a & 1525 a \\
\hline Brachiaria ruziziensis & 107 a & 40,37 a & 1505 a \\
\hline Eleusine coracana + Crotalaria spectabilis & 108 a & $39,49 \mathrm{~b}$ & $1504 \mathrm{a}$ \\
\hline Pennisetum glaucum + Raphanus sativus & $110 \mathrm{a}$ & 40,42 a & 1483 a \\
\hline Crotalaria spectabilis & $110 \mathrm{a}$ & $39,04 \mathrm{~b}$ & $1470 \mathrm{a}$ \\
\hline Crotalaria juncea & 109 a & 39,84 a & 1456 a \\
\hline Pousio & 107 a & 39,07 b & $1444 \mathrm{a}$ \\
\hline Pennisetum glaucum & $104 \mathrm{a}$ & $40,27 \mathrm{a}$ & 1439 a \\
\hline Avena strigosa & $108 \mathrm{a}$ & $40,04 \mathrm{a}$ & $1399 \mathrm{~b}$ \\
\hline Sorghum bicolor & $108 \mathrm{a}$ & $38,33 \mathrm{~b}$ & $1390 \mathrm{~b}$ \\
\hline Eleusine coracana & 109 a & $38,31 \mathrm{~b}$ & $1384 \mathrm{~b}$ \\
\hline Raphanus sativus & $104 \mathrm{a}$ & 39,37 b & $1283 \mathrm{~b}$ \\
\hline Avena strigosa + Raphanus sativus & $103 \mathrm{a}$ & $38,64 \mathrm{~b}$ & $1263 \mathrm{~b}$ \\
\hline C.V. (\%) & 4,56 & 2,75 & 8,76 \\
\hline
\end{tabular}

Grupo de médias seguidas pela mesma letra, na coluna, não diferem entre si, pelo teste de Scott-Knott, a 5\%. 


\section{CONCLUSÕES}

As espécies Brachiaria ruziziensis, B. ruziziensis + Crotalaria juncea, B. ruziziensis + Crotalaria spectabilis e $P$. glaucum $+R$. sativus, semeadas após a colheita da soja, produzem adequada quantidade de biomassa seca para semeadura direta do algodão.

A biomassa seca da $B$. ruziziensis, cultivada de forma solteira ou consorciada com $C$. juncea e com $C$. spectabilis, apresenta boa persistência e propicia boa cobertura do solo ao longo do ciclo do algodoeiro.

A produção de biomassa seca das espécies $B$. ruziziensis, B. ruziziensis + Crotalaria juncea e $B$. ruziziensis $+C$. spectabilis, semeadas em safrinha após colheita da soja, dificulta a infestação de plantas daninhas até a época de semeadura do algodão e reduz a incidência de plantas daninhas durante os estádios iniciais de desenvolvimento do algodoeiro.

Palha de $R$. sativus, A. strigosa e do consórcio de ambas as espécies interfere negativamente na produtividade do algodoeiro.

\section{AGRADECIMENTOS}

Ao Fundo de Incentivo à Cultura do Algodão em Goiás - FIALGO, e à EMBRAPA, pelo apoio financeiro.

\section{REFERÊNCIAS}

Aita, C \& Giacomini, SJ (2003) Decomposição e liberação de nitrogênio de resíduos culturais de plantas de cobertura de solo solteiras e consorciadas. Revista Brasileira de Ciência do Solo, 27:601-612.

Almeida, FS \& B.N. Rodrigues (1995) Guia de herbicidas: recomendações para o uso adequado em plantio direto e convencional. IAPAR, Londrina. 482p.

Alvarenga, RC, Lara C, WA, Cruz, JC \& Santana; DP (2001) Plantas de cobertura de solo para sistema plantio direto. Informe Agropecuário, 22:25-36.

Borkert, CM, Gaudêncio, CA, Pereira, JE, Pereira, LR, \& Oliveira Jr, A (2003) Nutrientes minerais na biomassa da parte aérea em culturas de cobertura do solo. Pesquisa Agropecuária Brasileira, 38:143-153.

Calegari, A, Mondardo, A, Bulisani, EA, Costa, MBB da, Myasaka, S \& Amado, TJC (1993) Aspectos gerais da adubação verde. In: Costa, M.B.B. da. (Coord.). Adubação verde no sul do Brasil. 2. ed. Rio de Janeiro, AS-PTA. p.1-56.

Canossa, RS, Oliveira Jr, RS, Constantin, J, Biffe, DF, Alonso, DG \& Franchini, LHM (2007) Profundidade de semeadura afetando a emergência de plântulas de Alternanthera tenella. Planta Daninha, 25:719-725.

Corrêa, JC \& Sharma, RD (2004) Produtividade do algodoeiro herbáceo em plantio direto no cerrado com rotação de culturas. Pesquisa Agropecuária Brasileira, 39:41-43.

Correia, N M (2005) Palhas de sorgo associadas ao herbicida imazamox no controle de plantas daninhas na cultura da soja em sucessão. Planta Daninha, 23:483-489.
Correia, NM \& Durigan, JC (2004) Emergência de plantas daninhas em solo coberto com palha de cana-de-açúcar. Planta Daninha, 22:11-17.

De-Polli, H \& Chada, SS de. (1989) Adubação verde incorporada ou em cobertura na produção de milho em solo de baixo potencial de produtividade. Revista Brasileira de Ciência do Solo, 13:287-293.

Fageria, NK \& Stone, CF (2004) Produtividade de feijão no sistema plantio direto com aplicação de zinco. Pesquisa Agropecuária Brasileira, 39:73-78.

Ferreira, AC de B, Lamas, FM, Carvalho, MCS, Barbosa, KA \& Teobaldo, AS (2007) Avaliação de coberturas vegetais semeadas na primavera e suas influências sobre o algodoeiro. In: VI Congresso Brasileiro de Algodão, Uberlândia. Anais, AMIPA. CD-ROM.

Fleck, NG, Bianchi, MA, Rizzardi, MA \& Agostinetto, D (2006) Interferência de Raphanus sativus sobre cultivares de soja durante a fase vegetativa de desenvolvimento da cultura. Planta Daninha, 24:425-434.

Floss, EL (2000) Benefícios da biomassa de aveia ao sistema plantio direto. Revista Plantio Direto, 57:25-29.

Heckler, JC; Hernani, LC; Pitol, C (1998) Palha. In: Salton J.C., Hernani, L.C. \& Fontes, C.Z. (Org.). Sistema plantio direto: o produtor pergunta, a Embrapa responde. Dourados, EMBRAPACPAO. p.37-49.

Hernani, LC, Salton, JC (2001) Manejo e conservação do solo. In: Algodão: tecnologia de produção. Dourados, Embrapa Agropecuária Oeste; Embrapa Algodão. p.76-102.

Lacerda, ALS, Victoria Filho, R \& Mendonça, CG (2005) Levantamento do banco de sementes em dois sistemas de manejo de solo irrigados por pivô central. Planta Daninha, 23:1-7.

Lamas, FM (2007) Espécies para cobertura do solo e seus efeitos no algodoeiro. Revista Brasileira de Oleaginosas e Fibrosa, 11:55-63.

Lamas, FM \& Staut, LA (2006) Algodoeiro em sistema plantio direto. Dourados, Embrapa Agropecuária Oeste. 8p. (Embrapa Agropecuária Oeste. Comunicado Técnico, 118).

Marur, CJ \& Ruano, O (2001) A reference system for determination of developmental stages of upland cotton. Revista de Oleaginosas e Fibrosas, 5:313-317.

Mateus, GP, Crusciol, CAC \& Negrisloi, E (2004) Palhada de sorgo guiné gigante no estabelecimento de plantas daninhas em áreas de plantio direto. Pesquisa Agropecuária Brasileira, 39:539-542.

Meschede, DK; Ferreira, AB \& Ribeiro Jr, CC (2007) Avaliação de diferentes coberturas na supressão de plantas daninhas no Cerrado. Planta Daninha, 25:465-471.

Nunes, UR, Andrade Jr, Silva, E de B, Santos, NS, Costa, HAO \& Ferreira, CA (2006) Produção de palhada de plantas de cobertura e rendimento do feijão em plantio direto. Pesquisa Agropecuária Brasileira, 41:943-948.

Pavinato, A (2005) Entraves para a cultura do algodoeiro em sistema plantio direto. In: $8^{\circ}$ Encontro de Plantio Direto no Cerrado. Tangará da Serra. Anais, Tangará da Serra, Gráfica e Editora Sanches Ltda., p.162 -166.

Pitelli, RA (1997) Dinâmica de plantas daninhas no sistema plantio direto. In: Simpósio sobre Herbicidas e Plantas Daninhas, Dourados. Anais, EMBRAPA-CPAO. p.50-61.

Richetti, A (2007) Estimativa de custo de produção de algodão, safra 2007/2008, para Mato Grosso do Sul e Mato Grosso. Dourados, Embrapa Agropecuária Oeste. 16p. (Comunicado Técnico, 136).

Yenish, JP, Doll, JD, Buhler, DD (1992) Effects of tillage on vertical distribution and viability of weed seed in soil. Weed Science, 40:429-433. 